[Agr. Biol. Chem., Vol. 35, No. 8, p. 1259 1266, 1971]

\title{
Chloroplast Development in 4-Thiouridine Treated Radish Cotyledons ${ }^{+, t \dagger}$
}

\author{
By Hideo Ochial, Hitoshi SHIbata and Takahiro Suekane \\ Laboratory of Biochemistry, College of Agriculture, \\ Shimane University, Matsue, Shimane, Japan \\ Received February 22, 1971
}

\begin{abstract}
Formation of protochlorophyllide and ribulose-1,5-diphosphate carboxylase, both of which were constituents proper to chloroplast, was inhibited in the radish cotyledons grown with 4-thiouridine $(0.5 \mathrm{mM})$, though the growth of the seedlings, activities of a cytoplasmic enzyme glucose-6-phosphate dehydrogenase and of a mitochondrial enzyme glutamate dehydrogenase in the cotyledones were not affected. Photo-induced formation of chlorophyll pigments and of chloroplastic ribosomal RNAs in the 4-thiouridine treated cotyledones were depressed as compared with controls. Interestingly, the effect of 4-thiouridine, however, disappeared with continuous illumination. Based upon these results, specific development of the chloroplast is discussed.
\end{abstract}

We have recently focused our interest on studies of the photo-induced development of the photosynthetic organelles in higher plants, and have demonstrated the inhibitory effect of $4 \mathrm{sU}$ on chloroplast development of radish cotyledons in a preliminary report, ${ }^{11}$ which was the first description of the physiological action of $4 \mathrm{~s} \mathrm{U}$ in a higher plant. The photo-induced formation of chloroplasts in etiolated plants has been observed by many investigators to proceed independently of non-photo-synthetic organelles using antibiotics such as actinomy-

+ Presented partly at the annual meeting of Agricultural Chemical Society of Japan (Fukuoka, April 1st, 1970).

I† Abbreviations: 4sU, 4-thiouridine; $\mathrm{PCH}$, protom chlorophyllide; $\partial$-ALA, $\partial$-Amino levulinic acid; ATA, 3-amino-1,2,4-triazole; Sandoz 6706, 4-chloro-5-(dimethylamino)-2-( $\alpha, \alpha, \alpha$-trifluoro- $m$-tolyl)-3(2H)-pyridazinone; G6PDH, glucose-6-phosphate dehydrogenase [E.C.1.1.1.49]; GluDH, glutamate dehydrogenase [E.C.1.4.1.3]; RuDP, ribulose-1,5-diphosphate.

1) H. Ochiai and H. Shibata, Agr. Biol. Chem., 34, 1751 (1970).

2) B. A. Melandri, A. Baccarini and G. Forti, Plant Physiol., 44, 95 (1969).

3) R. W. Pollack and P. J. Davies, Phytochemistry 9, 471 (1970). cin $\mathrm{D},{ }^{2)}$ chloramphenicol, ${ }^{3)}$ streptomycin, ${ }^{4)} p$ chlorophenyl dimethylurea, ${ }^{51}$ tentoxin $^{61}$ and Sandoz 6706," all of which are irreversible type toxins.

The inhibitory effect of $4 \mathrm{sU}$ followed by the restoration on illumination is one approach to investigating the mechanism of photoinduced development of chloroplasts. We report experimental results on chloroplast development of $4 \mathrm{~s} \mathrm{U}$ treated radish cotyledons.

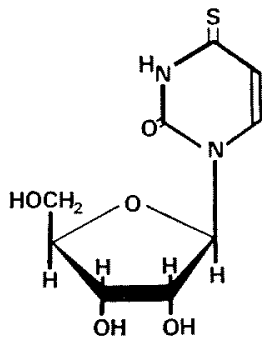

FIG. 1. 4-Thiouridine (4sU).

4) J. Ingle, Plant Physiol., 43, 1850 (1968).

5) D. McMahon and L. Bogorad, ibid., 43, 188 (1968).

6) J. M. Halloin, G. A. deZoeten, G. Goard and J. C. Walker, ibid., 45, 310 (1970),

7) P. G. Bartels and A. Hyde, ibid., 45, 807 (1970). 


\section{MATERIALS AND METHODS}

Materials and culture conditions. Radish seeds (Raphanus sativus Linn.) were obtained from Takii Shubyo Co. Ltd., Kyoto, and $4 \mathrm{sU}$ was synthesized from uridine after the methods of Fox et al.,8) and purified by cellulose column chromatography using isopentyl alcohol-acetone-water $(3: 2: 1$ by volume) as the solvent. ${ }^{9}$ The $4 \mathrm{sU}$ thus obtained contained no uridine, 2-thiouridine and 2,4-dithiouridine.

Radish seeds were allowed to germinate on absorbent cotton in Petri dishes containing $0.5 \mathrm{~mm} 4 \mathrm{sU}$ in $1 \mathrm{mM}$ phosphate buffer at $\mathrm{pH} 7.0$, unless otherwise noted, in the dark at $22^{\circ} \mathrm{C}$ for 4 days. The etiolated seedlings obtained were illuminated with Mitsubishi fluorescent lamps (4000 lux) at $22^{\circ} \mathrm{C}$ for the desired time. Controls were left under the same conditions except for the presence of $4 \mathrm{sU}$.

Chlorophylls were extracted with $80 \%$ acetone and were determined by measuring optical density of the extract at $665 \mathrm{~m} \mu$ following Arnon's method.10 PCH was determined by measuring the optical density of the acetone extract at $625 \mathrm{~m} \mu$ according to Siegelman's method.11; Molar extinction coefficients of both pigments were $\varepsilon_{665}=73.3 \times 10^{3}$ and $\varepsilon_{625}=31.1 \times$ $10^{3}$, respectively. Carotenoids were extracted from the cotyledons with acetone and the extracts were evaporated in vacuo to give a solid substance, which was then extracted with ether. The ether solution was treated overnight with $1 \%$ potassium hydroxide in methanol. Water was added to the reaction mixture, and the upper layer (ether) was washed 4 times with saturated sodium chloride aq. solution, then dried on anhydrous sodium sulphate. Carotenoids were determined by measuring the optical density of the ether solution at $446 \mathrm{~m} \mu$. The amount of carotenoid was calculated as $\beta$-carotene using $E_{446}^{1 \%} \mathrm{~m} \mu=2.5 .12$

Enzyme preparation and assay method. Crude enzymes prepared after Klein's method ${ }^{13}$ ) were used for the

8) J. J. Fox et al., J. Am. Chem. Soc., 81, 178 (1959).

9) V.N. Shibaev et al., "Synthetic Procedures in Nucleic Acid Chemistry," ed. by W. W. Zorbach and R. S. Tipson, Interscience Publishers, New York, N.Y., 1968 p. $503 \sim 505$.

10) D. I. Arnon, Plant Physiol., 24, 1 (1949).

11) P. Schopfer and H. W. Siegelman, ibid., 43, 990 (1968).

12) F. P. Zscheile, et al., Plant Physiol., 17, 331 (1942).

13) B. Filner and A. O. Klein, ibid., 43, 1587 (1968). assays of G6PDH and GluDH. A $1.5 \mathrm{~g}$ portion of fresh cotyledons was cut up, placed in a homogenizer (Nippon Seiki HA-2) then were homogenized in $12 \mathrm{ml}$

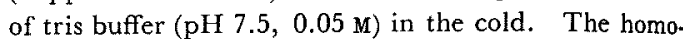
genate was squeezed through 4 layers of gauze and the sap obtained was centrifuged at $20,000 \times g$ for $10 \mathrm{~min}$ in the cold. The supernatant was passed through a Sephadex G-25 column, and its effuent was assayed for G6PDH activity according to Kornberg's method.14 Specific activity was determined by measurement of $\Delta E_{340} / \mathrm{mg}$ of protein for the initial $3 \mathrm{~min}$ using NADP+ as cofactor. In addition, the sap obtained above was frozen and thawed 4 times, then centrifuged at $20,000 \times g$ for $10 \mathrm{~min}$ in the cold and treated with * Sephadex G-25 column. The protein solution obtained was used for the assay of GluDH according to Bücher's method.15) Specific activity was determined in a manner similar to the G6PDH assay but using NAD+ as cofactor. For the assay of RuDP carboxylase [E.C.4.1.1.39] activity, a sample was homogenized in $0.05 \mathrm{M}$ tris buffer ( $\mathrm{pH} 8.0$ ) containing $0.2 \mathrm{mM}$ EDTA, then it was centrifuged at $12,000 \times g$ for $10 \mathrm{~min}$. The protein solution obtained was used for the assay following a modification of the method of Klein.12) The reaction mixture contained tris buffer ( $\mathrm{pH} 8.0$ ) $5 \mu$ moles, RuDP $0.5 \mu$ moles, enzyme protein $0.7 \mathrm{mg}$, and sodium bicarbonate $25 \mu$ moles $\left({ }^{14} \mathrm{C}-\mathrm{NaHCO}_{3}\right.$ $1.0 \mu \mathrm{Ci}$ ) in a total volume of $0.4 \mathrm{ml}$. Fifteen minutes after the addition of the labelled bicarbonate, $0.1 \mathrm{ml}$ of $10 \%$ perchloric acid was added. The reaction mixture was centrifuged and $0.1 \mathrm{ml}$ of the supernatant solution was dried on a planchette and its radioactivity was determined with a $2 \pi$-gas flow counter (Aloka FC-1E).

Protein. Protein was determined colorimetrically by the method of Lowry et al. ${ }^{16}$ )

$\delta$-ALA determination. Quantitative determination of $\delta$-ALA was performed according to Wada's method, ${ }^{17}$ A trace amount of $\delta$-ALA in the sample was deter-

14) A. Kornberg and B. L. Horecker, "Methods in Enzymology," Vol. 1, ed. by S. P. Colowick and N. O. Kaplan, Academic Press Inc., New York, N.Y., 1955 p. 323.

15) Th. Bücher et al., Z. Naturforsh., 8b, 555 (1953).

16) O. H. Lowry, N. J. Rosenbrough, A. L. Farr and R. J. Randaell, J. Biol. Chem., 193, 265 (1951).

17) O. Wada et al., Brit. J. industr. Med., 26, 240 (1969). 
mined as follows. After the addition of a known amount of $\delta$-ALA to an unknown sample, the $\delta$-ALA was determined and an estimation was made for a net amount of $\delta$-ALA in the unknown.

RNA preparations and analysis by polyacrylamide gel electrophoresis. The preparation of RNAs from the cotyledons was performed using the method described by Loening. ${ }^{18)}$ RNAs were determined by measuring their ultraviolet absorptions. The ratio of $260 \mathrm{~m} \mu /$ $280 \mathrm{~m} \mu$ of the isolated RNAs was 1.82 2.20. Analysis of the RNAs by polyacrylamide gel electrophoresis was performed according to the method of Peacock which used composite gels with $3 \%$ polyacrylamide containing $0.15 \%$ bisacrylamide and $0.5 \%$ agarose. ${ }^{19}$ After the prerun for $30 \mathrm{~min}$, the RNAs sample $(30 \mu \mathrm{g})$ was applied to the vertical gel $(5 \times 70 \mathrm{~mm})$ and electrophoresis was begun at $5 \mathrm{~mA}$ per tube for $150 \mathrm{~min}$ in a cold room. When the run was over, the gels were stained in $0.2 \%$ methylene blue as described by Peacock. ${ }^{201}$ Destaining was done by pouring off the excess stain and washing the gel for $24 \mathrm{hr}$ with running water. The stained pattern on the gel was quantitatively estimated using a densitometer fixed with a $610 \mathrm{~m} \mu$ filter (Asuka Ozumor 82). ${ }^{21}$ )

\section{RESULTS}

Figure 2 shows the growth curves of 50 radish seedlings grown with or without $0.5 \mathrm{mM}$ $4 \mathrm{sU}$ in the control buffer. In both total body weight and cotyledon weight, there is no or little difference between $4 \mathrm{sU}$ treated plants and controls, showing that $4 \mathrm{~s} U(0.5 \mathrm{~mm})$ did not affect germination followed by growth of the plants.

Chlorophylls as well as carotenoids of the seedlings cultured with and without $4 \mathrm{~s} U$ were determined. The data shown in Fig. 3 indicate that $4 \mathrm{sU}$ inhibited normal greening, as compared with controls, especially at the early

18) U. E. Loening and J. Ingle, Nature, 215, 363 (1967).

19) A. C. Peacock and C. W. Dingman, Biochemist$r y, 7,668$ (1968).

20) A. C. Peacock and C. W. Dingman, ibid., 6, 1818 (1967).

21) H. Ochiai and H. Shibata, Bull. Faculty of Agr. Shimane Univ., 4, 120 (1970) (in Japanese).

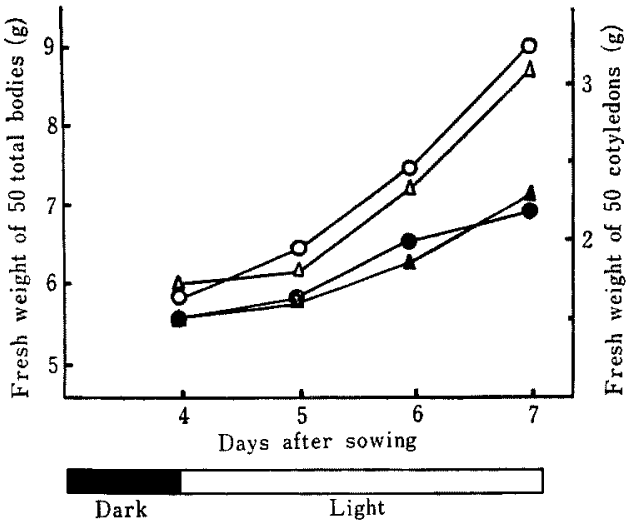

FIG. 2. Growth Curves of Radish Seedlings.

$\mathrm{O}-\mathrm{O}$; Total body grown without $4 \mathrm{sU}$

$\triangle-\triangle$; Total body grown with $4 \mathrm{sU}$

--); Cotyledon grown without $4 \mathrm{sU}$

$\Delta-\mathbf{A}$; Cotyledon grown with $4 \mathrm{sU}$

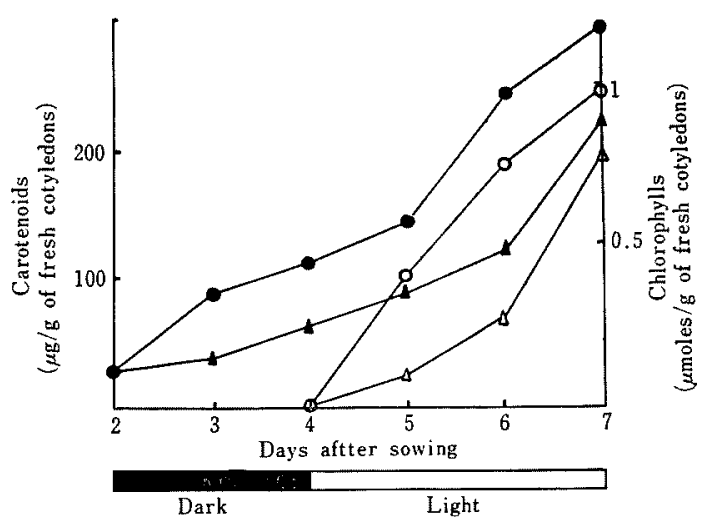

FIG 3. Determination of Chlorophylls and Carotenoids in Cotyledons Cultured with and without $4 s \mathrm{U}$.

-- Carotenoids without $4 \mathrm{sU}$

$\Delta-\Delta$; Carotenoids with $4 \mathrm{sU}$

O-O; Chlorophylls without $4 \mathrm{sU}$

$\triangle-\triangle$, Chlorophylls with $4 \mathrm{sU}$

stage, but greening was restored by 3 days of illumination. Determinations of carotenoids demonstrated that both cotyledons grown with and without $4 \mathrm{~s} U$ contained carotenoids, though to a lesser extent in the case of $4 \mathrm{~s} U$ treated dark-grown seedlings. Carotenoids content 
TABLE I. EFFECT of Some REagents on ChLorophyll Formation

\begin{tabular}{lcccccc} 
& $\begin{array}{c}\text { Water } \\
(\mathrm{dark})\end{array}$ & $\begin{array}{c}\text { Water } \\
(\mathrm{light})\end{array}$ & $\begin{array}{c}4 \mathrm{sU} \\
(\mathrm{l} \mathrm{mM})\end{array}$ & $\begin{array}{c}\text { Uridine } \\
(\mathrm{l} \mathrm{mM})\end{array}$ & $\begin{array}{c}\text { Glutathione } \\
(1 \mathrm{mM})\end{array}$ & $\begin{array}{c}\text { 2-Thiouracil } \\
(\mathrm{m} \mathrm{m})\end{array}$ \\
\hline Chlorophylls/g of fresh cotyledons $(\mu \mathrm{g})$ & 2 & 452 & 430 & 492 & 444 & 302 \\
\hline
\end{tabular}

Cotyledons cultured without $4 \mathrm{~s} U$ in the dark for 4 days were excised and incubated with the reagents (1 $\mathrm{mM}$ ) shown above in the dark for $12 \mathrm{hr}$; then they were illuminated (6,000 lux) for $24 \mathrm{hr}$. Chlorophyll formation was determined by methods described in "Materials and Methods" "Water (dark)" means incubation with water in the dark.

rose in a way similar to that for chlorophylls on illumination. The fact that dark-grown cotyledons treated with $4 \mathrm{sU}$ contained carotenoids suggests that the action of $4 \mathrm{sU}$ is different from that of ATA $^{41}$ or Sandoz 6706, which resulted in albino leaves.

Bartels showed that the albino wheat leaves derived from the treatment of Sandoz 6706 could not develop chloroplasts on illumination at "high" intensity, suggesting the importance of carotenoids as "chemical buffer" or photoprotector to prevent photolysis or bleaching of chlorophylls." The radish cotyledons grown with $4 \mathrm{sU}$ in the dark for 4 days contained about $60 \%$ as much carotenoids as did the controls. The control cotyledons growing for 2.5 days in the dark contained carotenoids as much as did the $4 s \mathrm{U}$ treated ones grown for 4 days in the dark and these showed normal development of the chloroplast upon illumination. This suggests that the smaller content of carotenoids in the $4 \mathrm{sU}$ treated cotyledons did not cause the retarded greening in our experiment.

Normal cotyledons grown in the dark for 4 days were excised and incubated with various reagents for $12 \mathrm{hr}$ in the dark, then were illuminated (6000 lux) for $24 \mathrm{hr}$ and chlorophyll formation was determined. The data shown in Table I indicate that $4 \mathrm{sU}$ had no inhibitory effect on the greening of excised normal cotyledons, so that the contact of the seeds with $4 \mathrm{sU}$ in the germination stage should be primarilly related to the inhibition of the greening on illumination. Uridine exerted only a slight promoting effect and 2-thiouracil pro-

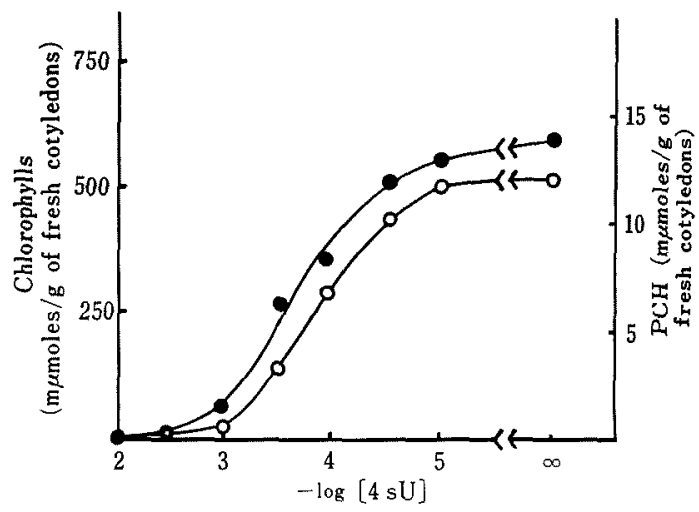

FIG. 4. Content of PCH in Cotyledons Grown in Various Concentrations of $4 \mathrm{sU}$ in the Dark for 4 Days, and Chlorophylls Formation in Cotyledons after Illumination for $24 \mathrm{hr}(6,000 \mathrm{lux})$.

$\mathrm{O}-\mathrm{O} ; \mathrm{PCH}$

--); Chlorophylls

duced an inhibitory effect on greening. ${ }^{221}$

Figure 4 shows the content of PCH, precursor of chlorophyll biogenesis, in the cotyledons grown with various concentrations of $4 \mathrm{~s} \mathrm{U}$ and photo-induced chlorophyll formation in the cotyledons after $24 \mathrm{hr}$ illumination (6000 lux). Both curves are almost parallel, indicating that treatment by a higher concentration of $4 \mathrm{sU}$ resulted in less content of $\mathrm{PCH}$ and less formation of chlorophylls on illumination.

On the other hand, $\delta$-ALA, a starting material for porphyrin pigments, such as chlorophylls and cytochromes, was shown to accumulate in $40 \pm 10 \%$ excess in the $4 \mathrm{~s} U$

22) J. Heslop-Harrison, Planta, 58, 237 (1962). 


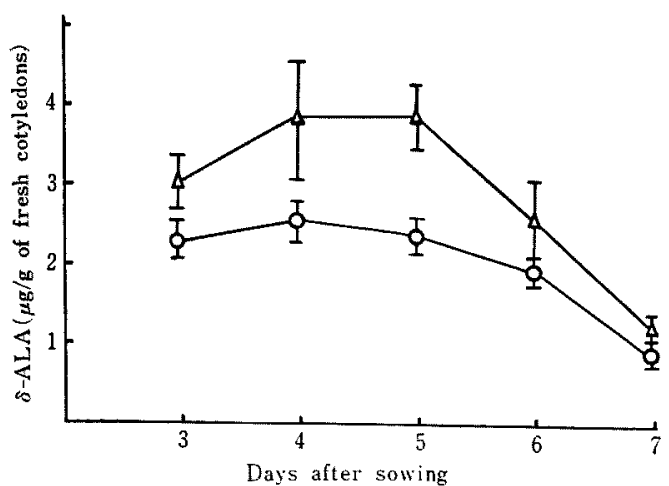

FIG. 5. Accumulation of $\delta$-ALA in Dark-grown Cotyledons Treated with and without $4 \mathrm{sU}$.

$\triangle-\triangle$; treated with $4 \mathrm{sU}$

$\mathrm{O}-\mathrm{O}$; treated without $4 \mathrm{sU}$

$(0.5 \mathrm{mM})$ treated cotyledons as compared with controls (Fig. 5). More recently Nadler and Granick $^{23 !}$ demonstrated that the enzymes synthesizing $\mathrm{PCH}$ from $\delta$-ALA in barley were not limiting even during the lag phase in the dark, and that the limiting activity for chlorcphyll synthesis appeared to be a protein (or proteins) related to the synthesis of $\delta$-ALA. The existence of $\delta$-ALA in excess and of PCH in lesser amounts in the $4 \mathrm{sU}$ treated cotyledons indicates that the formation of nonlimiting enzymes synthesizing PGH from $\delta$ ALA in the $4 \mathrm{sU}$ treated proplastids was arrested.

The specific activity of G6PDH, a typical enzyme in the soluble cytoplasm, was the same, in the cotyledons grown with $4 s U$, as the activity of controls. GluDH, a typical enzyme of mitochondria, also showed no difference in activity between the $4 \mathrm{~s} \mathrm{U}$ treated plants and controls as shown in Fig. 6. However, the specific activity of RuDP carboxylase, which is a proper enzyme of chloroplasts, was low in etiolated cotyledons germinated with $4 \mathrm{sU}$ but was significantly high in the cotyledons without $4 \mathrm{sU}$. In one experiment, $4 \mathrm{~s} \mathrm{U}$ was

23) K. Nadler and S. Granick, Plant Physiol., 46, 240 (1970).

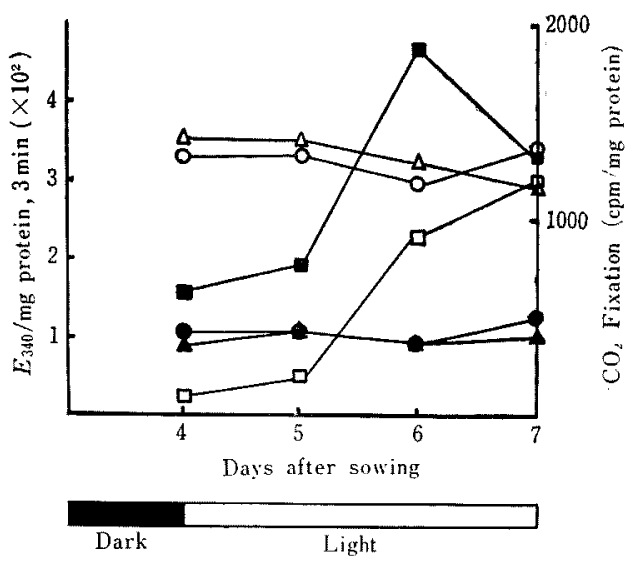

FIG. 6. Enzyme Activities in Cotyledons Cultured with and without $4 s \mathrm{U}$.

Assay conditions are described in the text.

$\mathrm{O}-\mathrm{O} ; \mathrm{G} 6 \mathrm{PDH}$ without $4 \mathrm{sU}$

$\triangle-\triangle ; \mathrm{G} 6 \mathrm{PDH}$ with $4 s \mathrm{U}$

-1 GluDH without $4 s \mathrm{U}$

$\Delta-\Delta ;$ GluDH with $4 \mathrm{sU}$

-1; RuDP carboxylase without $4 \mathrm{sU}$

$\square-\square$; RuDP carboxylase with $4 \mathrm{sU}$

added to RuDP carboxylase preparations obtained from control cotyledons, but the enzyme activity was not affected. This suggests that the low specific activity of the enzyme from $4 \mathrm{~s} U$ treated cotyledons was caused by the low formation of the enzyme in the plant.

Figure 7 shows the time course of RNA accumulation in the cotyledons treated with and without $4 \mathrm{sU}$. The accumulation of RNA in the cotyledons of the dark-grown, $4 \mathrm{sU}$ treated seedlings is less than that in the untreated until 6 days growth in the dark. However, the rate of RNA synthesis in the $4 \mathrm{sU}$ treated plants from 2 to 4 days growth in the dark is more rapid than that of the untreated ones. The accumulation of RNAs in the $4 \mathrm{sU}$ treated seedlings reached about $90 \%$ that of the untreated after 4 days growth in the dark. RNA synthesis in controls was shown to be stimulated by light, reaching a maximum value in the following $24 \mathrm{hr}$, whereas the rate of accumulation of the $4 \mathrm{~s} \mathrm{U}$ treated RNA was lower; needing $48 \mathrm{hr}$ to reach a 


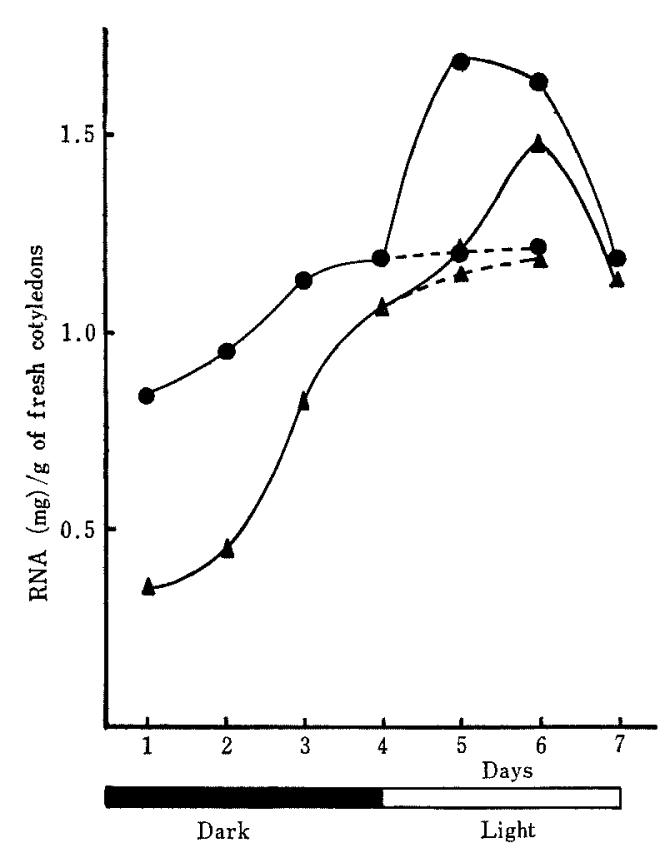

FIG. 7. Time Course of RNAs Accumulation in Cotyledons Cultured with and without $4 \mathrm{sU}$.

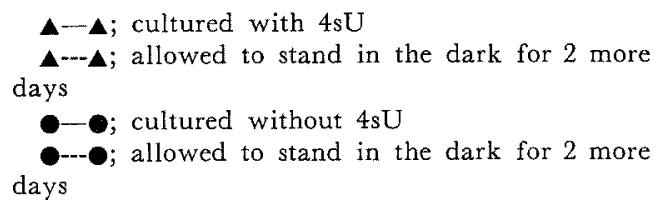

maximum value. These phenomena seem to correlate with the results shown in Fig. 8, which shows the fractionation on polyacrylamide gel electrophoresis of RNAs from cotyledons cultured with (inset $B, D, F$ and $\mathrm{H}$ ) and without $4 \mathrm{sU}$ (inset $\mathrm{A}, \mathrm{C}, \mathrm{E}$ and $\mathrm{G}$ ) at various developmental stages. According to Loening, ${ }^{181}$ the peaks shown in inset $\mathrm{C}$, for example, are assumed to be 25S, 23S, 18S, $16 \mathrm{~S}$ and 13S RNA, respectively, from right to left. Both 25S and 18S RNAs, cytoplasmic ribosomal RNAs, developed similarly both in controls and in $4 \mathrm{sU}$ treated cotyledons, respectively, grown in the dark for 4 days. A small amount of $23 \mathrm{~S}$ and 16S RNAs, chloroplastic ribosomal RNAs, are seen after 4 days growth
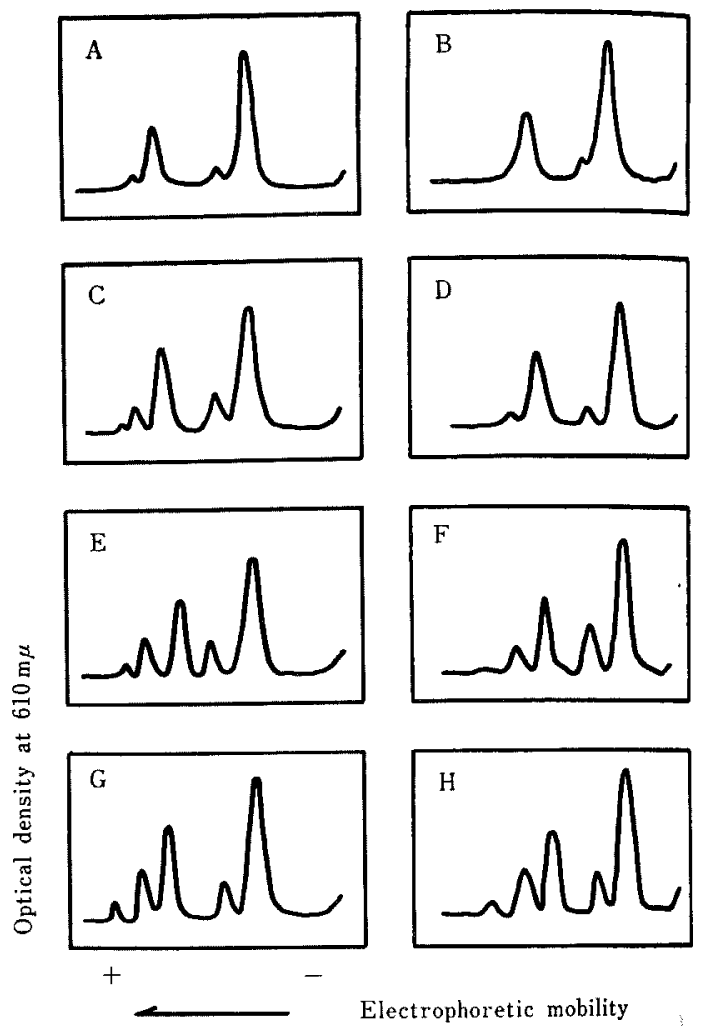

FIG. 8. Chromatograms of RNAs on Polyacrylamide Gel Electrophoresis of the Developmental Stage of Cotyledons Cultured with (Inset $\mathrm{B}, \mathrm{D}, \mathrm{F}$ and $\mathrm{H}$ ) and without $4 \mathrm{sU}$ (Inset $\mathrm{A}, \mathrm{C}, \mathrm{E}$ and $\mathrm{G}$ ).
$A$ and B: 4 days growth in the dark.
$\mathrm{C}$ and D: illuminated for $24 \mathrm{hr}$.
$\mathrm{E}$ and $\mathrm{F}$ : illuminated for $48 \mathrm{hr}$.
$\mathrm{G}$ and $\mathrm{H}$ : illuminated for $72 \mathrm{hr}$.

in the dark (inset A), while 16S RNA is not present in the $4 \mathrm{~s} U$ treated ones (inset $B$ ). Inset $\mathrm{C}$ shows the chromatogram of RNAs obtained from greening cotyledons of controls at $24 \mathrm{hr}$ illumination, demonstrating the appearence of 13S RNA. Over the same time intervals both 23 S and 16S RNAs but not 13S RNA appeared in the $4 \mathrm{~s} U$ treated cotyledons (inset D). Inset $F$ indicates that both $23 \mathrm{~S}$ and $16 \mathrm{~S}$ RNAs in the $4 s U$ treated cotyledons reached a nomal ratio to cytoplasmic RNA which was comparable to that of controls shown in inset 
E. From that time the chlorophyll content and carotenoid content increased as shown in Fig. 3. RNA patterns both in $4 \mathrm{sU}$ treated and in controls are similar after $72 \mathrm{hr}$ illumination (inset $\mathrm{H}$ and $\mathrm{G}$ ).

The results described above indicate that the development of chloroplastic ribosomal RNAs was selectively prevented by the presence of $4 \mathrm{sU}$.

\section{DISCUSSION}

The presence of $4 \mathrm{sU}$ as a minor constituent has been established in transfer RNAs from E. coli, ${ }^{24}$ from Mycoplasma ${ }^{251}$ and also in ribosomal RNAs from $E$. coli, ${ }^{26)}$ while the presence of $4 \mathrm{sU}$ in plant kingdom has not been reported yet.

It was demonstrated in this paper that the formation of $\mathrm{PCH}$ and RuDP carboxylase, both proper constituents of chloroplasts, were inhibited in radish seedlings grown with $4 \mathrm{sU}$ $(0.5 \mathrm{mM})$, though the growth, the activity of a cytoplasmic enzyme G6PDH and the activity of a mitochondrial enzyme GluDH in these seedlings were not affected. Photo-induced formation of chlorophylls and of chloroplastic ribosomal RNAs in $4 s \mathrm{U}$ treated cotyledons were depressed as compared with those of controls. Interestingly, the activity of RuDP carboxylase, the formation of chlorophylls and of chloroplastic ribosomal RNAs were restored to their normal values by continuous illumination. In the $4 \mathrm{sU}$ treated cotyledons, the accumulation of $\mathrm{PCH}$ was reduced to $30 \%$, while $\delta$-ALA, a starting material for chlorophyll and cytochrome pigments, was accumulated $40 \pm 10 \%$ in excess, as compared with controls. The results show that 4 s $\mathrm{U}$ selectively prevented the formation of chloroplastic enzymes in the cotyledons grown in the dark

24) M. N. Lipsett, J. Biol. Chem., 240, 3975 (1965).

25) H. Hayashi, H. Fisher and D. Söll, Biochemist$r y, 8,3680$ (1969).

26) J. H. Parish, P. A. Fletcher and M. Brown, Biochem. J., 110, 39 P (1968). followed by growth in the light. Furthermore, based upon the results obtained from the behaviors of RNAs on polyacrylamide gel electrophoresis, we concluded that $4 \mathrm{sU}$ depressed photo-induced chloroplastic RNA synthesis, which should be a prior process to the formation of either enzymes ${ }^{27 !}$ or structural proteins ${ }^{28}$ in chloroplasts. This supports the hypotheses that the enzymatic or structural proteins involved in chloroplast development are formed on the chloroplastic ribosomal RNAs and also that chloroplasts are semiautonomous organelles.

More recently Pollack et al. ${ }^{31}$ investigated the developmental kinetics of cytoplasmic and chloroplastic ribosomal RNA and chlorophyll in normal pea buds upon transfer from dark to light, and demonstrated that chloroplastic ribosomal RNA showed no lag period in its rate of formation, while chlorophyll showed a lag of $24 \mathrm{hr}$ after initiation of the light, which suggests that there is a direct dependence of the production of chlorophyll on the amount and appearance of chloroplastic ribosomal RNA. This is also true of our $4 \mathrm{sU}$ treated radish cotyledons.

These phenomena might be related to the biochemical property of $4 \mathrm{~s} U$ as a thiol nucleoside and/or to the photo-chemical property of $4 \mathrm{sU}$ as a photosensitizer, which has a maximum, absorption at $330 \mathrm{~m} \mu$. It was demonstrated that ribosomes of $E$. coli which were shown to contain $4 \mathrm{sU}$-phosphate as a constituent of the ribosomal RNA by Parish et al. ${ }^{267}$ could be dissociated reversibly into $50 \mathrm{~S}$ and $30 \mathrm{~S}$ subunit by treatment with $p$-chloromercuribenzoic acid. ${ }^{291}$ On the other hand, ribosomes of Pseudomonas aeruginosa and Bacillus subtilis which contained no detectable amount of $4 \mathrm{sU}$ phosphate were shown to be insensitive to the thiol reagent. Parish, therefore, concluded

27) M. Gassman and L. Bogorad, Plant Physiol., 42, 774 (1967).

28) J. T. O. Kirk, Planta, 78, 200 (1968).

29) F. Miyazawa and T. Tamaoki, J. Mol. Biol., 24, 485 (1967). 
that $4 \mathrm{sU}$ moiety in the $E$. coli ribosomes must have contributed to the stability of $70 \mathrm{~S}$ ribosomes. The presence of $4 \mathrm{~s} \mathrm{U}$ in plant kingdom has not been reported yet, but it is assumed that the stability of chloroplastic ribosomes (70S) may be influenced by the presence of $4 \mathrm{sU}$, thiol nucleoside. In addition, Sawada demonstrated that bovine pancreatic ribonuclease [E.C.2.7.7.16] was inactivated by irradiation with ultraviolet light of $330 \sim 365 \mathrm{~m} \mu$ in the presence of a substrate analogue, $4 s \mathrm{U}-2(3)$ phosphate. $^{301}$ The proplastid or chloroplast, in our experiments, might preferentially suffer from the inhibitory effect by $4 \mathrm{sU}$ due to its higher sensitivity to $4 \mathrm{sU}$ or to its poorer metabolic activity of $4 \mathrm{sU}$. What step(s) of chloroplastic RNA synthesis undergo the inhibitory effect of $4 \mathrm{~s} \mathrm{U}$ is not clear. The

30) F. Sawada, J. Biochem., 65, 767 (1969). question remains as to whether the $4 s U$ in the plant acts either as such or as any metabolite of $4 \mathrm{sU}$. Investigations of these problems are in progress in our laboratory.

Moreover, the mechanism by which the selective effect of $4 \mathrm{sU}$ disappeared during continuous illumination needs to be determined. One of us demonstrated that $4 \mathrm{sU}$ showed specific photochemical behaviour distinguished from other constituents of RNAs. ${ }^{311}$ One possible explanation of the detoxication is that $4 \mathrm{sU}$, free or bound in the plant, might receive photo-induced transition into uridine via uridine-4-sulfonic acid, ${ }^{32}$ based on the photochemical properties of $4 \mathrm{sU}$.

31) M. Pleiss, H. Ochiai and P. A. Cerutti, Biochem. Biophys. Res. Comm., 34, 70 (1969).

$32)$ E. B. Ziff and J, R. Fresco, J.Am. Chem. Soc. 90, 7338 (1968). 